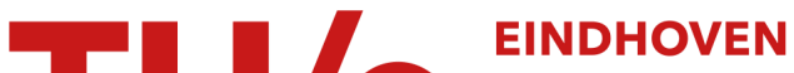 \\ UNIVERSITY OF \\ TECHNOLOGY
}

\section{Entrepreneurship at the interface of design and science}

\section{Citation for published version (APA):}

Romme, A. G. L., \& Reymen, I. M. M. J. (2018). Entrepreneurship at the interface of design and science: Toward an inclusive framework. Journal of Business Venturing Insights, 10, 1-8. [e00094].

https://doi.org/10.1016/j.jbvi.2018.e00094

DOI:

10.1016/j.jbvi.2018.e00094

Document status and date:

Published: 01/11/2018

\section{Document Version:}

Accepted manuscript including changes made at the peer-review stage

\section{Please check the document version of this publication:}

- A submitted manuscript is the version of the article upon submission and before peer-review. There can be important differences between the submitted version and the official published version of record. People interested in the research are advised to contact the author for the final version of the publication, or visit the $\mathrm{DOI}$ to the publisher's website.

- The final author version and the galley proof are versions of the publication after peer review.

- The final published version features the final layout of the paper including the volume, issue and page numbers.

Link to publication

\section{General rights}

Copyright and moral rights for the publications made accessible in the public portal are retained by the authors and/or other copyright owners and it is a condition of accessing publications that users recognise and abide by the legal requirements associated with these rights.

- Users may download and print one copy of any publication from the public portal for the purpose of private study or research.

- You may not further distribute the material or use it for any profit-making activity or commercial gain

- You may freely distribute the URL identifying the publication in the public portal.

If the publication is distributed under the terms of Article 25fa of the Dutch Copyright Act, indicated by the "Taverne" license above, please follow below link for the End User Agreement:

www.tue.nl/taverne

Take down policy

If you believe that this document breaches copyright please contact us at:

openaccess@tue.nl

providing details and we will investigate your claim. 


\title{
Entrepreneurship at the interface of design and science: Toward an inclusive framework *
}

\author{
Forthcoming in: Journal of Business Venturing Insights
}

July 2018

\author{
A. Georges L. Romme \\ Eindhoven University of Technology \\ a.g.l.romme@tue.nl \\ Isabelle M.M.J. Reymen \\ Eindhoven University of Technology \\ I.M.M.J.Reymen@tue.nl
}

* An earlier version of this paper was presented at the workshop "Combining Rigor and Relevance: Entrepreneurship Theory as Design and Social Mechanisms”, May 2017, at Chalmers University of Technology. The authors are very grateful to two reviewers and Henrik Berglund for providing feedback on an earlier version of this paper. 


\title{
Entrepreneurship at the interface of design and science: Toward an inclusive framework
}

\begin{abstract}
Entrepreneurship scholars are increasingly interested in conducting work at the interface of design and science. However, a consistent methodological framework for this type of work is missing. In this paper, we therefore develop such a framework. First, three examples of entrepreneurship scholarship at the design-science interface are outlined. From these examples, we infer two key characteristics of design science (DS). For one, research outputs not only include theoretical constructs and models, but also values, principles and practices. In addition, creative design and scientific validation are complementary and equivalent research activities in DS. Whereas design and validation are legitimate research approaches in their own right, we conclude that the interaction between the two can drive the continual renewal of the entrepreneurship field and unlock the potential of an inclusive body of knowledge that is both rigorous and relevant.
\end{abstract}




\section{Introduction}

Scholarship in the field of entrepreneurship and management has long been characterized by an intellectual stasis, resulting in a limited capacity to inform practice (Davidsson, 2002; Hughes et al., 2011; Khurana and Spender, 2012). This intellectual stasis also explains why the field of entrepreneurship is rather fragmented (cf. Shane, 2012; Venkataraman et al., 2012) and why academic and experiential knowledge on entrepreneurship are, at best, loosely connected (Romme, 2016).

Therefore, entrepreneurship scholars are increasingly becoming interested in doing work at the interface of design and science (e.g. Berglund et al., 2018; Dimov, 2016; Osterwalder, 2004; Sarasvathy et al., 2008). In The Sciences of the Artificial, Simon (1969) identified two properties of key phenomena studied by scholars in fields like business, education and architecture: human intentionality and environmental contingency. Simon argued that these two properties make an exclusively 'scientific' approach inadequate for studying these phenomena. Evidently, human intentionality and environmental contingency are at the heart of entrepreneurship practice and scholarship. Entrepreneurial artifacts such as value propositions and business models are inextricably linked to the entrepreneurial intentions driving them, and moreover, cannot be decoupled from the environmental settings in which they were created and the environmental conditions expected in the future. Furthermore, entrepreneurship scholarship also arises from personal intentions and academic values that inform and frame how, for example, one collects and interprets data, interacts with entrepreneurs and entrepreneurship students, and responds to unexpected events and setbacks in academic life. As such, the properties of human intentionality and environmental contingency imply that entrepreneurship research is a science of the artificial, that is, it involves both creative design and scientific validation. 
More recently, Simon's initial set of ideas were re-introduced in the discourse on the purpose and nature of management and entrepreneurship studies (e.g. Hatchuel, 2001; Romme, 2003; Sarasvathy, 2003; Sarasvathy and Venkataraman, 2011), which in turn may serve to develop a more inclusive 'design science' perspective on the field of entrepreneurship, also inspired by similar perspectives in adjacent fields (e.g. March and Smith, 1995). However, a consistent methodological framework for entrepreneurship research as design science is still missing (cf. Dimov, 2016; Sarasvathy, 2003; Venkataraman et al., 2012). In this paper, we intend to develop such a framework. This design science (DS) framework explicitly acknowledges the key contributions of scientific or design work in their own right, but also calls for scholarship at the interface between science and design.

As such, entrepreneurial phenomena lend themselves to a scientific as well as a design approach. Their processes unfold over time and one inevitably has to choose a time reference point (e.g. now, or somewhere in the past) in studying them (McMullen and Dimov, 2013). This reference point creates an arbitrary separation between what has already happened and what is yet to happen, both of which can serve as objects of research. A specific outcome, such as (a failed effort in) a new venture, can be described and explained retrospectively, as an object of science (cf. March and Smith, 1995). By contrast, the open-ended prospective process that lies ahead offers few dimensions that can be taken for granted. Thus, most scholars with social science backgrounds are only interested in the acting entrepreneur when patterns and/or outcomes have surfaced which can become the object of description and explanation. Here, a DS perspective can help connect retrospective and prospective approaches.

An inclusive classification of key notions and terms is an essential prerequisite for developing this perspective. Without an inclusive taxonomy, a more comprehensive understanding of the entrepreneurship (research) landscape cannot be developed. This paper 
involves an attempt to create such a framework, in order to facilitate collaboration and dialogue between entrepreneurship scholars across existing paradigmatic boundaries as well as, in the longer run, prospectively enable entrepreneurs and their stakeholders to effectively address their most pertinent challenges.

The argument is organized as follows. First, we explore three examples of DS research in the entrepreneurship domain. These examples set the stage for developing a comprehensive framework of how, why and when various research outputs are created, assessed, theorized and justified in DS. Finally, we discuss how this framework may serve to better connect theory and practice by systemically connecting rigor and relevance.

\section{Examples of work at the design-science interface}

This section serves to outline several examples of entrepreneurship research at the interface between science and design. In particular, we refer to DS scholarship in the area of business modeling, entrepreneurial effectuation, and university spinoffs.

\subsection{Business modeling}

A prominent example of DS is Osterwalder and Pigneur's (2010) business model canvas, arising from Osterwalder's (2004) doctoral work. Informed by the DS framework developed by March and Smith (1995) for the field of information systems, Osterwalder (2004) explored how business models can be described and represented, to create a foundation for subsequent tool development. He conducted interviews with entrepreneurs, investors and other experts, which revealed that "business models were perceived as a tool to create a commonly understood language to improve communication and understanding of the fundamental questions of a business” (Osterwalder, 2004, p. 159). Thus, a more rigid conceptual approach to business models appeared to be necessary. Osterwalder therefore systematically reviewed and synthesized the literature to develop a so-called ‘business model ontology' involving four 
key dimensions (e.g. product, customer interface) and nine key constructs (e.g. value proposition, target customer, distribution channel) and their relationships. Osterwalder implemented this initial framework in a computer-based tool, and tested the resulting prototype in a case study.

After completing his doctoral dissertation, Osterwalder set out to further develop the business modeling framework, via prototyping processes that involved the active contributions of more than 450 practitioners, resulting in the 'business model canvas' (Osterwalder and Pigneur, 2010). This large-scale effort to co-create and iteratively develop prototypes of the canvas provides a good example of how academic knowledge on entrepreneurship is successfully developed into practical tools.

\subsection{Effectuation}

Another interesting example of design science work in the entrepreneurship field is Sarasvathy's (2001; 2003) work on effectuation. In her doctoral thesis, Sarasvathy raised hypothetical scenarios to 27 successful entrepreneurs, by asking them to 'think aloud' about how they would approach a particular start-up proposition. From these data, she then (offline) extracted design principles for entrepreneurial effectuation: for example, the 'bird in hand' and 'affordable loss’ principles (Sarasvathy, 2001). These design principles have been informing the redesign and transformation of entrepreneurship education and training programs at many schools and universities throughout the world (e.g. Honig, 2004; Read et al., 2010). The original empirical work of Sarasvathy has also been extended toward knowledge and tools for novice managers and executives (Read et al., 2009). Other studies have focused on the performance consequences of the set of effectuation principles (e.g. Fischer and Reuber, 2011) and connecting the effectuation principles to other theoretical frameworks regarding opportunity, action, cognition, finance, operations, and strategy (e.g. Read and Dolmans, 2012; Sarasvathy et al., 2008). 
Many of the ideas arising from the effectuation lens are still open to empirical operationalization and testing. However, the core idea is that self-selected stakeholders can bring together their own unique means and values, to combine these in efforts to construct an artifact that cannot be predicted at the outset. Some recent work focuses more on the balance between effectuation as a flexible decision-making logic and causation as a planning-based logic for decision-making, to investigate the dynamics in how both logics are used (Berends et al., 2014; Reymen et al., 2015; Reymen et al., 2017). These insights guide practitioners to judge when to use effectuation or causation, and how to combine the effectual and causal principles.

\subsection{Spinoff creation}

The third example is the study of university spinoff creation conducted by Van Burg et al. (2008) at a university of technology, whose senior management was looking for ways to improve the university's performance in creating spinoff firms. A team of entrepreneurship scholars was invited to develop evidence-based guidelines for spin-off creation, and then evaluate how the current design of the university’s new business incubator could be changed or improved (Van Burg et al., 2008). A design science approach (Romme and Endenburg, 2006) was adopted to develop design principles that would connect research findings and entrepreneurial practices. These principles were developed in three steps. First, practicebased principles were inferred from the existing incubation practice at the university, by extracting and explicating the largely tacit knowledge of key actors. Second, a systematic literature review served to develop research-based principles. Subsequently, these two sets of principles were synthesized, resulting in several principles that were evidence-based as well as contextualized for a (European) university of technology, for example: "Set clear and supportive rules and procedures that regulate the university spin-off process, enhance fair 
treatment of the parties involved, and separate spinoff processes from academic research and teaching” (Van Burg et al., 2008, p. 123).

These principles were subsequently used to improve the incubation practices of the incumbent university. The principles developed by Van Burg et al. (2008) were also replicated by Barr et al. (2009) in a study of several US-based universities, and extended by Lackéus and Williams Middleton’s (2011) study of other venture creation programs in Europe, North America and Asia-Pacific. Moreover, many other studies have collected (additional) empirical evidence for one or two of the principles identified by Van Burg and coauthors (e.g. Bell and Bell, 2016; Johnson et al., 2017; Muscio et al., 2016). For example, Johnson et al.'s (2017) findings lend further support to the guideline regarding universitywide role models in entrepreneurial behavior developed by Van Burg et al. (2008). The initial study by Van Burg and co-authors also served to define research gaps informing subsequent studies of transparency and fairness in spin-off creation (e.g. Van Burg et al., 2013; Van Burg and Van Oorschot, 2013).

\section{Entrepreneurship as design science}

The studies outlined in the previous section illustrate the variety and richness of DS research. Each of these studies was also informed by a different DS framework. Osterwalder employed the framework that March and Smith (1995) developed for the field of information systems, whereas Sarasvathy’s work was largely inspired by The Sciences of the Artificial (Simon, 1969), and Van Burg and coauthors used the framework developed by Romme and Endenburg (2006) in the field of organization studies. Thus, a DS framework for the entrepreneurship field is not yet available, which in turn may undermine progress toward a coherent body of knowledge on entrepreneurship (cf. Abbott, 1988). Therefore, we develop such a framework for the field of entrepreneurship and new business venturing. We infer this 
framework from the three exemplary studies outlined in section 2 as well as the taxonomies developed for adjacent fields by March and Smith (1995) and Romme (2016).

First, studies at the interface of design and science appear to embrace a broad array of potential research in- and outputs, including theoretical constructs and models, but also values, principles and practices. Moreover, creative design and scientific validation appear to be complementary research activities. These two dimensions, research in/outputs and research activities, are dissected in more detail in the remainder of this section.

\subsection{Research inputs and outputs}

The examples in section 2 suggest that DS research embraces a broader set of research outputs than the typical outputs arising from mainstream entrepreneurship science. For example, the three studies not only draw conventional outputs such as theoretical constructs and models, but also develop (design) principles for shaping practices. Moreover, the studies outlined in the previous section appear to draw on values that go beyond notions such as validity and reliability.

To capture this variety, we distinguish between five types of research output: values, constructs, models, principles, and practices (adapted from: March and Smith, 1995; Romme, 2016). Here, research output refers to both input and output in the remainder of this article, because they are largely synonymous. In this respect, the iterative nature of entrepreneurship research implies that the preliminary output from one research phase (e.g. constructs inferred from the literature) often serves as input to the next phase (e.g. developing a conceptual model); moreover, outputs from one project are often used as inputs in subsequent projects.

A value denotes the degree of importance a particular action or opportunity has for an individual scholar or practitioner; for example, it serves to determine which opportunities are identified, but also how one evaluates, selects and acts upon them (Moroz et al., 2018). As 
such, values are a key mechanism guiding professional work, regardless of whether this is work as an entrepreneur, investor, (entrepreneurship) scholar, or other capacity. Notably, the idea that entrepreneurship research should be 'value-free', in terms of an exclusive focus on describing and explaining the objective reality 'out there', is in itself a value-based decision: it prioritizes the explanation of existing reality, rather than seeking to contribute to efforts to transform that reality (Argyris, 1993). As such, DS scholarship is driven by values such as the need "to create things that serve human purposes" (Osterwalder, 2004: 4) and the "dual purpose” to improve the performance as well as to understand the underlying processes of the entity being study (Van Burg et al., 2008: 118). This suggests values need to be acknowledged as a separate category of research in/output.

Constructs constitute the vocabulary for describing a particular set of entrepreneurial problems and challenges. Most constructs in entrepreneurship research involve concepts or variables that cannot be directly observed: for example, ‘value proposition’, 'distribution channel’, 'affordance', or 'partnership’ (e.g. Osterwalder and Pigneur, 2010; Sarasvathy, 2001). These constructs therefore need to be operationalized, estimated or approximated.

A model involves a set of propositions or statements expressing relationships among constructs. This broad definition includes conceptual frameworks, mathematical models, and 'theories' (as defined by Shapira, 2011) and thus captures the variety of narrative, mathematical and statistical approaches used in entrepreneurship research. Moreover, this definition not only incorporates explanatory and descriptive models, but also instrumental models such as the business model canvas (e.g. Osterwalder and Pigneur, 2010), lean startup (Ries, 2011) and other frameworks (e.g. Thomke and Manzi, 2014). We deliberately avoid the label ‘theory', arguing that 'theorizing' (as research activity, discussed later) not only applies to constructs and models, but also to values, principles and practices (Romme, 2016). 
Principles, also known as design principles, involve solution-oriented guidelines for a certain entrepreneurial problem or challenge, that is, the "real helps" of entrepreneurial thought and action (Sarasvathy and Venkataraman, 2011, p. 130). Principles in the area of entrepreneurship tend to be heuristic and metaphorical in nature (e.g. Sarasvathy’s 'bird in hand' or 'affordable loss' principle), but can also be explicitly developed in terms of, for example, the CMO format: in context $\mathrm{C}$, mechanism $\mathrm{M}$ is likely to generate outcome pattern O (Van Burg and Romme, 2014). For instance, in their study of spinoff creation by universities, Van Burg and coauthors (2008) present a set of principles for growing the capability to create spinoff firms (O) in publicly funded universities (C), including the guideline to help starters obtain access to resources (M) and develop their social capital (M) by creating a collaborative network of investors, managers, and advisors around the university.

As this example demonstrates, a principle is typically composed of multiple constructs, but also goes beyond these constructs. As such, constructs and principles are fundamentally different in terms of their functionality as (intermediary) research output: constructs primarily serve an analytical function, by dissecting complex patterns and phenomena into smaller elements; by contrast, principles primarily serve to synthesize research findings in the service of entrepreneurial practice (e.g. Van Burg et al., 2012).

Finally, a practice involves the application or instantiation of values, constructs, models, and/or principles in an entrepreneurial context. In this respect, any practice can be considered to be an instantiation of values, constructs, models and/or principles, regardless of whether or not these are explicitly defined, codified or theorized (prospectively or retrospectively). Moreover, entrepreneurship practices can be tangible or intangible in nature; examples are activities in around pilot projects, product prototyping, pitching to investors, contracting with suppliers and distributors, developing customer databases, shaping and testing business 
models, and so forth (e.g. Mansoori, 2017; Osterwalder and Pigneur, 2010; Read and Dolmans, 2012). As such, entrepreneurship researchers themselves also engage in many 'practices', such as questionnaire development, writing research papers, presenting at conferences, and reporting to funding agencies. Thus, the notion of practice (as research in/output) proposed here embraces a rather diverse set of practical activities and the tangible or intangible artifacts arising from these activities; this serves to avoid a more restrictive notion of practice, as often used in adjacent fields (e.g. Bromiley and Rau, 2014; Gherardi, 2000).

Figure 1 presents the five types of research outputs as slices of a larger body of knowledge, to emphasize that each of these research outputs is essential to a professional body of knowledge on entrepreneurship. Notably, each of the five categories can be further differentiated in subcategories, but a taxonomy of five categories is appropriate in the context of the argument here.

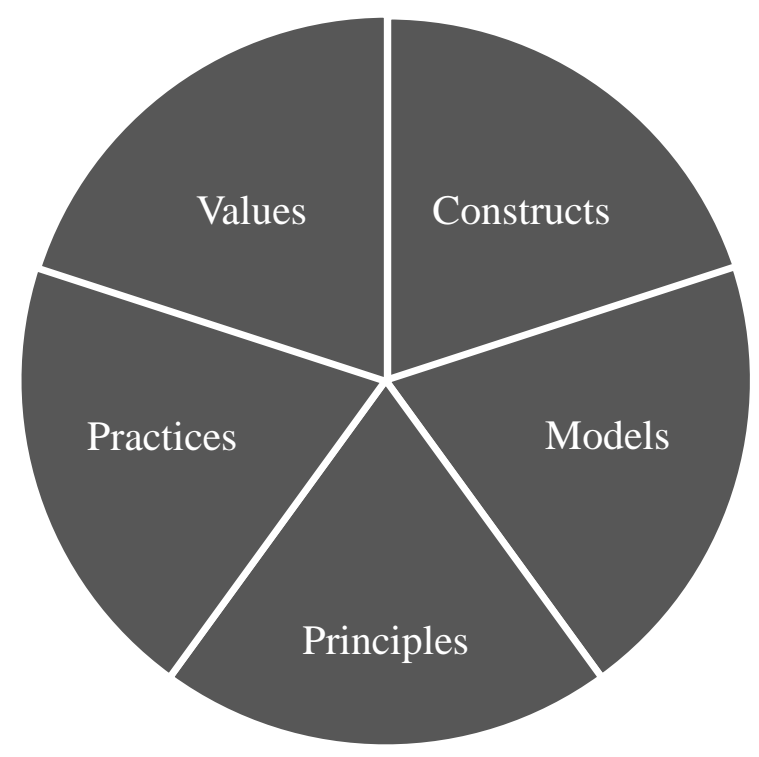

Fig. 1. Research in/outputs: values, constructs, models, principles, and practices. 


\subsection{Research activities}

Having defined an inclusive set of research outputs, we now turn to how these research outputs are used and produced. The three examples outlined in section 2 suggest that DS scholarship involves both creative design and scientific validation, as complementary and equivalent research activities. Design is not only about creating new entrepreneurial practices or changing established practices into new ones, but it also involves developing new kinds of knowledge (in terms of values, constructs, models and/or principles) about these practices; moreover, it may also involve creating knowledge about practices that 'might be' or 'should be'. Once a new practice and/or knowledge about this practice has been developed, validation serves to codify, fine-tune, generalize, justify and (possibly) falsify it.

We can further differentiate this high-level categorization into creating and evaluating (together: design) and theorizing and justifying (together: validation), following March and Smith (1995). Figure 2 provides an overview of the resulting research cycle. Creating involves the initial act of conceiving a value, construct, model, principle or practice that is (perceived as) new. For example, a critical step in developing the effectuation perspective was to create a set of effectual constructs and principles, based on a 'think-aloud' experiment with 27 expert entrepreneurs (Sarasvathy 2001; Read and Dolmans, 2012). In their study of spinoff creation, Van Burg and coauthors (2008) took the incubation practices that had already been created by the university’s TTO office as a starting point.

Evaluating refers to the act of assessing one or more of these research outputs against (value-based) criteria such as usefulness, feasibility, viability, desirability and novelty (e.g. Brown, 2008). The acts of creation and evaluation often go together, with many iterations back and forth, as is evident from how the business model canvas (model) originated from its preliminary shape in Osterwalder's doctoral thesis, and its further development by Osterwalder and Pigneur (2010), based on feedback and input from hundreds of practitioners 
who tried out a version of the canvas and evaluated it in terms of usefulness and related criteria. Another example is Van Burg et al's (2008) study of spinoff creation, in which the initial set of practice-based principles was evaluated by the practitioners involved in the incubator unit.

Theorizing is about producing propositions or statements that are generalizable as well as applicable to, or testable on, individual cases. Effectuation, for example, has been theorized to be a function of meta-cognitive expertise development (Read and Dolmans, 2012; Read and Sarasvathy, 2005) and the process and outcomes of spinoff creation have been conceptualized and analyzed using fairness theory (e.g. Van Burg et al., 2013; Van Burg and Van Oorschot, 2013).

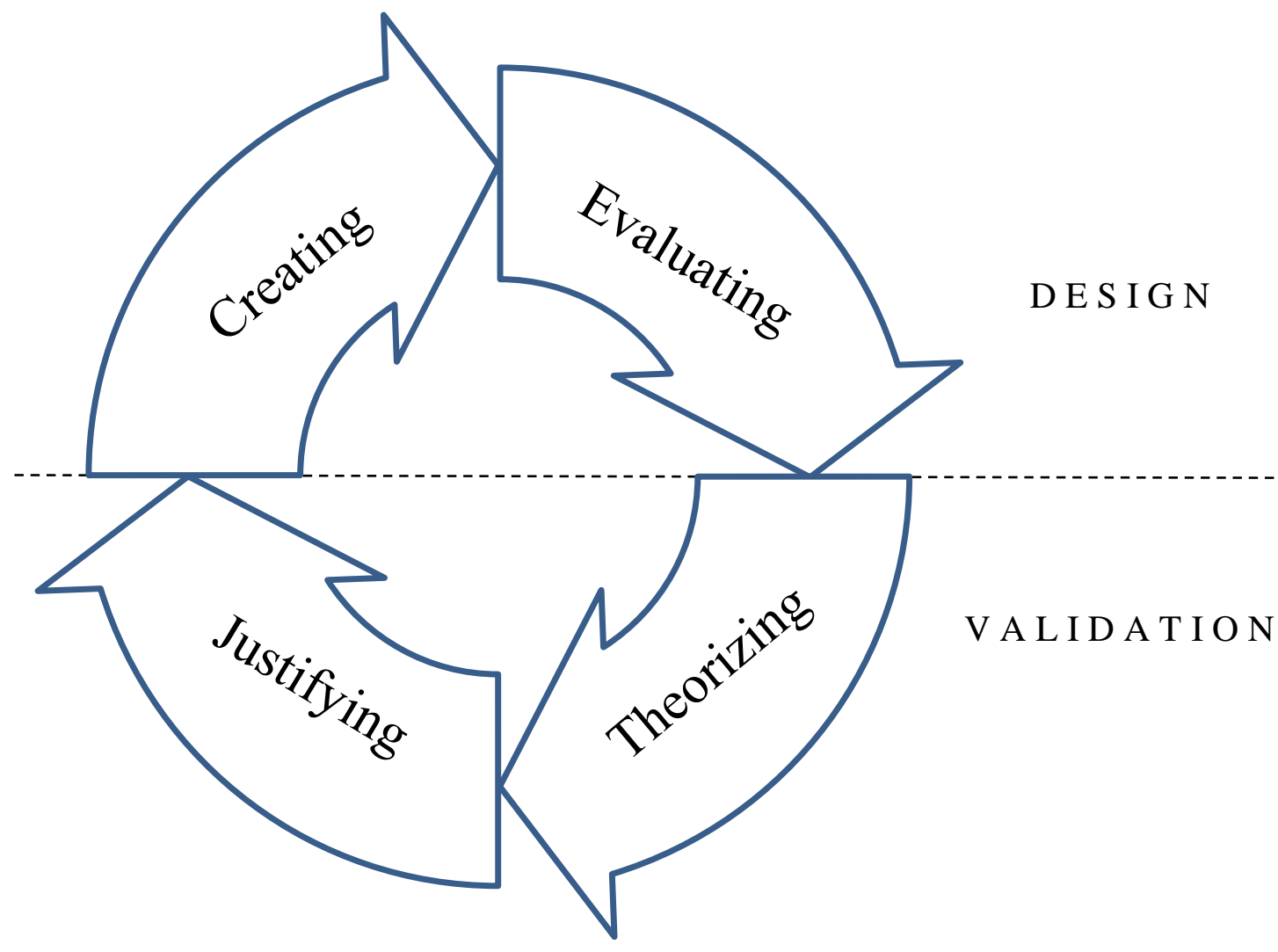

Fig. 2. Research activities (incl. methods): creating, evaluating, theorizing, and justifying. 
Finally, justifying involves any effort to enhance the legitimacy of a particular research output, by assessing the research output against criteria such as generalizability, internal and external validity, and reliability. For example, Osterwalder (2004) developed his initial set of constructs based on a systematic literature review, to assure that the results were a valid representation of the extant literature on business models. And Sarasvathy's initial principles and model of effectuation were later replicated with a sample of novice managers (Dew et al., 2009), which served to confirm the uniqueness of effectual heuristics used by expert entrepreneurs (Read and Dolmans, 2012). Notably, we concur with March and Smith (1995) by using the notion of 'justifying' rather than 'testing'. In this respect, the notion of testing can be used in so many different ways and stages of the DS research cycle (e.g. prototyping and pilot-testing an artifact, scrutinizing by means of inferential statistics, pitching a value proposition to investors, and so forth), that it is rather meaningless as a generic research activity (see also section 3.3). Figure 2 provides a visual overview of the iterative nature of the four research activities that together enable a viable discourse on entrepreneurship.

\subsection{An inclusive framework of entrepreneurship as design science}

By putting the two dimensions outlined in Figure 1 and 2 together, we can create a map of the territory of entrepreneurship research and practice conceived as a design science. Figure 3 provides a visual image of how entrepreneurship can be conceived as a discipline at the interface of science and design. The framework in this figure serves to explicitly acknowledge that entrepreneurship is inherently value driven. Moreover, it provides ample opportunities to embrace practical and applied work as a key element of the body of knowledge on entrepreneurship, and helps to resolve some of the disputes around the notion of 'testing'.

First of all, Figure 3 serves to emphasize that all entrepreneurship research is inherently value-driven. It entails a framework for explicating and discussing key professional values in 
the field of entrepreneurship. More specifically, this figure implies that the complementarity of distinct values such as 'rigor' and 'relevance' is best exploited by addressing each value on its own terms. That is, the call for rigorous knowledge can be most effectively addressed in the lower half of Figure 3, whereas values such as novelty, desirability and relevance are best addressed in the upper half.

Although clearly articulated ethical values tend to increase employee satisfaction as well as organizational performance (e.g. Maurer et al., 2011; Moroz et al., 2018), the overall thrust of the entrepreneurship literature is validation-oriented, with few studies directly engaging in creating and evaluating values (e.g. Sarasvathy, 2001). As such, awareness of the value dimension is not widespread among entrepreneurship scholars; this is perhaps most conspicuous regarding values that (ideally) would need to guide the 'professional' behavior of management scholars and practitioners-particularly with regard to the complementarity between rigor and relevance and between understanding and application.

The framework in Figure 3 also provides ample opportunities to embrace practical and applied work as a key element of the body of knowledge on entrepreneurship. For example, many practitioners provide access to their reflections on their work by means of social media platforms (e.g. Inc.com), biographical reflections (e.g. Brandt, 2011), or blogs (e.g. Richard Branson's widely read blog). These insights in entrepreneurial practice arise from direct experience and reflection, typically without any systematically developing constructs, models and principles - but nonetheless are part of the emerging body of knowledge on entrepreneurship and business venturing.

In the context of the theorizing and justifying activities in Figure 3, entrepreneurship scholars often study practices and their broader conditions as empirical phenomena (e.g. Shapira, 2011). As discussed earlier, these empirical phenomena can be as varied as a customer database, narrative about the new venture’s proposition, code of employee conduct, 
or network of investors. However, entrepreneurial practices are often non-deliberative and impulse-driven, especially when entrepreneurs operate in highly ambiguous and fluid contexts (e.g. Lerner et al., 2018). These practices can thus (also) be conceived as artificial phenomena, especially when these practices are first created and evaluated (e.g. Meulman et al., 2018; Van Burg et al., 2008), as in upper half of Figure 3.

The framework outlined in Figure 3 also helps to resolve some of the disputes around what constitutes a proper 'test' in the field of entrepreneurship. For many entrepreneurship scholars, the notion of testing especially refers to ways to assess the internal and external validity of constructs and test hypotheses by means of inferential statistics (e.g. Coviello and Jones, 2004; Haber and Reichel, 2007; Levie and Autio, 2008). Other scholars adopt a narrative, constructivist view of knowledge that implies a focus on entrepreneurial action and sense making as genuinely creative and context-specific acts (e.g. Berglund, 2007; Chiles et al., 2007; Sarasvathy and Dew, 2005); assessing the authenticity and complexity of these acts is then given precedence over the goal of developing and testing general knowledge (Garud and Karnøe, 2003). A similar notion of testing is also evident in various instrumental models for supporting, guiding and training (nascent) entrepreneurs (e.g. Osterwalder and Pigneur, 2010; Ries, 2011; Sarasvathy, 2009; Thomke and Manzi, 2014), involving testing activities such as prototyping, developing proof-of-concepts, getting feedback from preferred witnesses, and pitching for investors. All these activities are about testing a value proposition regarding a customer problem or need, rather than a general theory-highly similar to the notion of alpha- and beta-testing used by software engineers (Van Aken and Romme, 2012). 


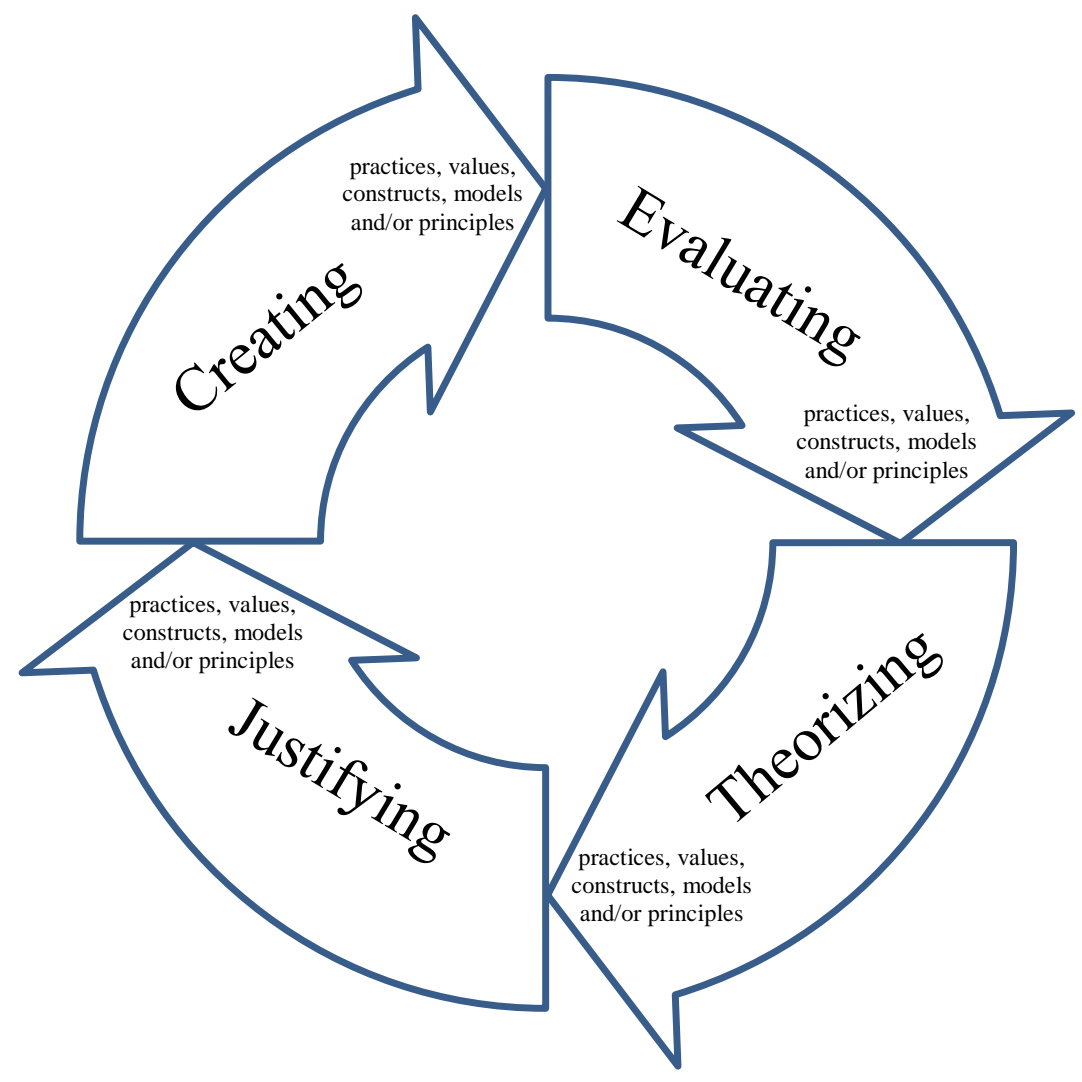

Fig. 3. Entrepreneurship research conceived as a discipline at the interface of science and design.

As such, mainstream entrepreneurship research draws on a notion of testing theory that is firmly embedded in the lower (validation) half of Figure 3, whereas critics of the validationoriented notions of theorizing and testing have argued that one needs to stop talking about theorizing and theory in the context of validation, and exclusively 'theorize' in the context of design- and discovery-oriented work (Sarasvathy and Venkataraman, 2011; Weick, 1989).

The set of definitions proposed in this paper combines key elements of the positions advocated by both sides. First, in section 3.1 we separated constructs and models as (theoretical) output from the research activities producing this output (cf. Weick, 1989). Second, our framework retains the 'theorizing' notion for the purpose of validation-oriented research (Shane, 2003; Shapira, 2011; Zahra et al., 2006), while providing a separate 
terminology for design-oriented research activities (Sarasvathy and Venkataraman, 2011; Venkataraman et al., 2012). Theorizing may thus involve, for example, codifying a particular value, using constructs and models to explain how or why a particular entrepreneurial practice has emerged, or using principles to brainstorm and speculate about whether an envisioned practice is likely to work.

As already observed in section 3.2, we deliberately do not use the ambiguous notion of testing at the level of the entire framework. Instead, we recommend that scholars and practitioners only talk about tests and testing in a very specific sense, that is, in the context of a single research activity focused on one or two outputs only. For example, the notion of testing used by many entrepreneurship scholars is about assessing the internal and external validity of constructs, test hypotheses (and the models these hypotheses are part of) by means of inferential statistics, and related methods. Therefore, Figure 3 implies this notion of testing can only be used in efforts to justify a specific model and/or set of constructs. By contrast, testing in form of getting feedback on a proposed business venture (e.g. from potential investors or lead customers) can be positioned in Figure 3 as an act of evaluating a particular practice, that is, an instantiation of the key values, constructs and principles driving this venture. Several other interpretations and applications of testing are appropriate in the context of other research outputs and activities.

As such, Figure 3 provides a framework that embraces the entire spectrum of 'testing' activities available in the entrepreneurship discipline. Rather than prioritizing one over the other, this framework suggests we appreciate and use each notion of testing in terms of its distinctive position in the knowledge chain of entrepreneurship as DS.

Notably, the DS framework presented in this section is primarily defined at the level of entrepreneurship as a (professional) body of knowledge, rather than individual projects. Section 2 outlined several examples of how DS has been applied at the (e.g. PhD) project 
level. Romme (2016) describes several other examples and also provides an overview of the research methods that can be used in designing and validating the various research outputs listed in Figure 1.

\section{Concluding remarks}

In this article we have explored how a design science (DS) perspective can help bridge the retrospective and prospective mindsets that both are critical to the field of entrepreneurship and business venturing. A framework was presented that connects an inclusive set of research activities in the area of design and validation to a broad portfolio of research in- and outputs (practices, values, constructs, models, principles).

The main thesis here is that the entrepreneurship discipline needs an inclusive methodology that systematically connects creative design and scientific validation. Design and validation are legitimate research approaches in their own right, but it is the powerful interaction between the two that drives the continual renewal of the entrepreneurship field and unlocks the potential of a body of knowledge that is both rigorous and relevant.

However, any sustained effort to develop and apply DS methodology is likely to encounter substantial resistance in and around business and management schools. Fifty years ago, Simon (1967) already observed that organizing a business school in an inclusive (DS) manner is very much like mixing oil with water: that is, it is rather easy to describe the recipe on paper, but rather difficult to actually produce it. Moreover, the task of mixing oil with water is not completed when the goal has been achieved (i.e. you get the two components mixed); left to themselves, water and oil will again start separating. As a result, combining design and validation is a continual administrative responsibility, requiring sustained attention and support by deans, group chairs, and research directors (Rousseau, 2012; Schön, 1987; Simon, 1967) as well as by external stakeholders, such as journal editors. 
Despite these major challenges, the examples outlined in this paper suggest that the DS perspective is becoming increasingly popular among entrepreneurship scholars. Thus, entrepreneurship scholars are well-positioned to act as frontrunners in ongoing efforts to reshape business and management schools and help realize their original founding purpose. 


\section{References}

Abbott, A., 1988. The System of Professions: An Essay on the Division of Expert Labor. University of Chicago Press, Chicago, IL.

Argyris, C., 1993. Knowledge for Action. Jossey-Bass, San Francisco, CA.

Barr, S.H., Baker, T., Markham, S.K., Kingon, A.I., 2009. Bridging the valley of death: lessons learned from 14 years of commercialization of technology education. Academy of Management Learning \& Education, 8, 370-388.

Bell, R., Bell, H., 2016. An enterprise opportunity for entrepreneurial students: student enterprise development and experience assessed through the student voice. Education + Training, 58, 751-765.

Berends, H., Jelinek, M., Reymen, I.M.M.J., Stultiens, R.G.L., 2014. Product innovation processes in small firms: combining entrepreneurial effectuation and managerial causation. Journal of Product Innovation Management, 31, 616-635.

Berglund, H., 2007. Opportunities as existing and created: a study of entrepreneurs in the Swedish mobile internet industry. Journal of Enterprising Culture, 15, 243-273.

Berglund, H., Dimov, D., Wennberg, K., 2018. Beyond bridging rigor and relevance: the three-body problem in entrepreneurship. Journal of Business Venturing Insights, 9, 87-91.

Brandt, R.L., 2011. The Google Guys: Inside the Brilliant Minds of Google Founders Larry Page and Sergey Brin. Portfolio/Penguin, New York.

Bromiley, P., Rau, D., 2014. Towards a practice-based view of strategy. Strategic Management Journal, 35, 1249-1256.

Brown, T. 2008. Design thinking. Harvard Business Review, 86(5), 84-92.

Chiles, T.H., Bluedorn, A.C., Gupta, V.K., 2007. Beyond creative destruction and entrepreneurial discovery: a radical Austrian approach to entrepreneurship. Organization Studies, 28, 467-493.

Coviello, N.E., Jones, M.V., 2004. Methodological issues in international entrepreneurship research. Journal of Business Venturing, 19, 485-508.

Davidsson, P., 2002. What entrepreneurship research can do for business and policy practice. International Journal of Entrepreneurship Education, 1, 5-24.

Dew, N., Read, S., Sarasvathy, S.D., Wiltbank, R., 2009. Effectual versus predictive logics in entrepreneurial decision-making: differences between experts and novices. Journal of Business Venturing, 24, 287-309.

Dimov, D., 2016. Toward a design science of entrepreneurship, in: Corbett, A.C., Katz, J.A., (Eds.), Models of Start-up Thinking and Action: Theoretical, Empirical, and Pedagogical Approaches. Advances in Entrepreneurship, Firm Emergence and Growth, vol. 18, pp. 131.

Fischer, E., Reuber, A.R., 2011. Social interaction via new social media: (how) can interactions on Twitter affect effectual thinking and behavior? Journal of Business Venturing, 26, 1-18.

Garud, R., Karnøe, P., 2003. Bricolage versus breakthrough: distributed and embedded agency in technology entrepreneurship. Research Policy, 32, 277-300.

Gherardi, S., 2000, Practice-based theorizing on learning and knowing in organizations. Organization, 7, 211-223.

Haber, S., Reichel, A., 2007. The cumulative nature of the entrepreneurial process: the contribution of human capital, planning and environment resources to small venture performance. Journal of Business Venturing, 22, 119-145.

Hatchuel, A., 2001. Towards design theory and expandable rationality: the unfinished program of Herbert Simon. Journal of Management and Governance, 5, 260-273. 
Hughes, T., Bence, D., Grisoni, L., O’Regan, N., Wornham, D., 2011. Scholarship that matters: academic-practitioner engagement in business and management. Academy of Management Learning \& Education, 10, 40-57.

Honig, B., 2004. Entrepreneurship education: toward a model of contingency-based business planning. Academy of Management Learning \& Education, 3, 258-273.

Johnson, M., Monsen, E.W., MacKenzie, N.G., 2017. Follow the leader or the pack? Regulatory focus and academic entrepreneurial intentions. Journal of Product Innovation Management, 34, 181-200.

Khurana, R., Spender, J.C., 2012. Herbert A. Simon on what ails business schools: more than 'a problem in organizational design.’ Journal of Management Studies, 49, 619-639.

Lackéus, M., Williams Middleton, K., 2011. Venture creation programs: entrepreneurial education through real-life content. Frontiers of Entrepreneurship Research, 31(9): article 8. Available at: https://digitalknowledge.babson.edu/fer/vol31/iss9/8

Lerner, D.A., Hunt, R.A., Dimov, D. 2018. Action! Moving beyond the intendedly-rational logics of entrepreneurship. Journal of Business Venturing, 33, 52-69.

Levie, J., Autio, E., 2008. A theoretical grounding and test of the GEM model. Small Business Economics, 31, 235-263.

Mansoori, Y., 2017. Enacting the lean startup methodology: the role of vicarious and experiential learning processes. International Journal of Entrepreneurial Behavior \& Research, 23, 812-838.

March, S.T., Smith, G.F., 1995. Design and natural science research on information technology. Decision Support Systems, 15, 251-266.

Maurer, C.C., Bansal, P., Crossan, M.M., 2011. Creating economic value through social values: introducing a culturally informed resource-based view. Organization Science, 22, 432-448.

McMullen, J.S., Dimov, D., 2013. Time and the entrepreneurial journey: the problems and promise of studying entrepreneurship as a process. Journal of Management Studies, 50, 1481-1512.

Meulman, F., Reymen, I.M.M.J., Podoynitsyna, K.S., Romme, A.G.L., 2018. Searching for partners in open innovation settings: how to overcome the constraints of local search. California Management Review, 60, 71-97.

Moroz, P.W., Branzei, O., Parker, S.C., Gamble, E.N. 2018. Imprinting with purpose: Prosocial opportunities and B Corp certification. Journal of Business Venturing, 33, 117129.

Muscio, A., Quaglione, D., Ramaciotti, L., 2016. The effects of university rules on spinoff creation: the case of academia in Italy. Research Policy, 45, 1386-1396.

Osterwalder, A., 2004. The Business Model Ontology - A Proposition in a Design Science Approach (doctoral dissertation). University of Lausanne, Lausanne.

Osterwalder, A., Pigneur, Y., 2010. Business Model Generation. Wiley, Hoboken, NJ.

Read, S., Sarasvathy, S.D., 2005. Knowing what to do and doing what you know: Effectuation as a form of entrepreneurial expertise. Journal of Private Equity, 9, 45-62.

Read, S., Sarasvathy, S.D., Song, M., Dew, N., Wiltbank, R., 2009. Marketing under uncertainty: A knock on the door. Journal of Marketing, 73, 1-18.

Read, S., Sarasvathy, S., Dew, N., Wiltbank, R., Ohlsson, A.V., 2010. Effectual Entrepreneurship. Routledge, New York.

Read, S., Dolmans, S.A.M., 2012. Effectuation 10 year waypoint. International Review of Entrepreneurship, 10, 25-46.

Reymen, I.M.M.J., Andries, P., Berends, H., Mauer, R., Stephan, U., Van Burg, J.C., 2015. Understanding dynamics of strategic decision-making in venture creation: a process study of effectuation and causation. Strategic Entrepreneurship Journal, 9, 351-379. 
Reymen, I.M.M.J., Berends, H., Oudehand, R., Stultiëns, R., 2017. Decision making for business model development: a process study of effectuation and causation in new technology-based ventures. R\&D Management, 47, 595-606.

Ries, E., 2011. The Lean Startup: How Today's Entrepreneurs Use Continuous Innovation to Create Radically Successful Businesses. Crown Business, New York.

Romme, A.G.L., 2003. Making a difference: Organization as design. Organization Science 14, 558-573.

Romme, G., 2016. The Quest for Professionalism: The Case of Management and Entrepreneurship. Oxford University Press, Oxford, UK.

Romme, A.G.L., Endenburg, G., 2006. Construction principles and design rules in the case of circular design. Organization Science, 17, 287-297.

Rousseau, D.M., 2012. Designing a better business school: Channelling Herbert Simon, addressing the critics, and developing actionable knowledge for professionalizing managers. Journal of Management Studies, 49, 600-618.

Sarasvathy, S.D., 2001. Causation and effectuation: toward a theoretical shift from economic inevitability to entrepreneurial contingency. Academy of Management Review, 26, 243263.

Sarasvathy, S.D., 2003. Entrepreneurship as a science of the artificial. Journal of Economic Psychology, 24, 203-220.

Sarasvathy, S.D., 2009. Effectuation: Elements of Entrepreneurial Expertise. Edward Elgar, Cheltenham, UK.

Sarasvathy, S.D., Dew, N., 2005. New market creation through transformation. Journal of Evolutionary Economics, 15, 533-565.

Sarasvathy, S.D., Dew, N., Read, S., Wiltbank, R. 2008. Designing organizations that design environments: lessons from entrepreneurial expertise. Organization Studies, 29, 331-350.

Sarasvathy, S.D., Venkataraman, S., 2011. Entrepreneurship as method: open questions for an entrepreneurial future. Entrepreneurship Theory and Practice, 35, 113-135.

Schön, D.A., 1987. Educating the Reflective Practitioner. Jossey-Bass, San Francisco, CA.

Shane, S., 2003. A General Theory of Entrepreneurship: The Individual-Opportunity Nexus. Edward Elgar, Cheltenham, UK.

Shane, S., 2012. Reflections on the 2010 AMR decade award: delivering on the promise of entrepreneurship as a field of research. Academy of Management Review, 37, 10-20.

Shapira, Z., 2011. "I've got a theory paper-do you?": conceptual, empirical, and theoretical contributions to knowledge in the organizational sciences. Organization Science, 22, 13121321.

Simon, H.A., 1967. The business school: A problem in organizational design. Journal of Management Studies, 4, 1-16.

Simon, H.A. (1969/1996). The Sciences of the Artificial (first edition published in 1969; third edition in 1996). MIT Press, Cambridge, MA.

Thomke, S., Manzi, J., 2014. The discipline of business experimentation. Harvard Business Review, 92(12): 70-79.

Van Aken, J.E., Romme, A.G.L., 2012. A design science approach to evidence-based management, in: Rousseau, D.M. (Ed.), The Oxford Handbook of Evidence-Based Management. Oxford University Press, New York, pp. 43-57.

Van Burg, J.C., De Jager, S., Reymen, I.M.M.J., Cloodt, M.M.A.H., 2012. Design principles for corporate venture transition processes in established technology firms. R\&D Management, 42, 455-472.

Van Burg, E., Romme, A.G.L., Gilsing, V.A., Reymen, I.M.M.J., 2008. Creating university spin-offs: a science-based design perspective. Journal of Product Innovation Management, $25,114-128$. 
Van Burg, E., Gilsing, V.A., Reymen, I.M.M.J., Romme, A.G.L., 2013. The formation of fairness perceptions in the cooperation between entrepreneurs and universities. Journal of Product Innovation Management, 30, 677-694.

Van Burg, E., Romme, A.G.L., 2014. Creating the future together: toward a framework for research synthesis in entrepreneurship. Entrepreneurship Theory and Practice, 38, 369397.

Van Burg, E., Van Oorschot, K.E., 2013. Cooperating to commercialize technology: a dynamic model of fairness perceptions, experience, and cooperation. Production and Operations Management, 22, 1336-1355.

Venkataraman, S., Sarasvathy, S.D., Dew, N., Forster, W.R., 2012. Reflections on the 2010 AMR decade award: whither the promise? Moving forward with entrepreneurship as a science of the artificial. Academy of Management Review, 37, 21-33.

Weick, K.E., 1989. Theory construction as disciplined imagination. Academy of Management Review, 14, 516-531.

Zahra, S.A., Sapienza, H.J., Davidsson, P. 2006. Entrepreneurship and dynamic capabilities: a review, model and research agenda. Journal of Management Studies 43, 917-955. 